The reason that Cross and Holmes found no effect on slices at physiological concentrations is a twofold action of the hormone. Using a molarity of $1 / 200000$ (which is $0.9 \mathrm{mgm}$./litre), a twofold effect can be seen if observations are made at several intervals of time. The treatment with adrenaline at first inhibits the synthesis of glycogen and later on increases it, thus masking the earlier effect. The following is a typical experiment.

SYNTHESIS OF MGM. GLYCOGEN PER GM. LIVER.

Liver slices from rabbit starved 39 hours $(2.68 \mathrm{mgm}$. glycogen $/ \mathrm{gm}$. liver) shaken in Krebs Ringer bicarbonate (1:6) $95 \%$ oxygen; $5 \%$ carbon dioxide ; $38^{\circ} \mathrm{C}$.; $0 \cdot 5 \%$ glucose.

\begin{tabular}{|c|c|c|c|}
\hline $\begin{array}{c}\text { Time } \\
\text { (min.) }\end{array}$ & $\begin{array}{c}\text { Synthesis } \\
\text { control }\end{array}$ & $\begin{array}{c}\text { Synthesis } \\
M / 200,000 \\
\text { adrenaline }\end{array}$ & $\begin{array}{c}\text { Effect of } \\
\text { adrenaline } \\
\text { (per cent) }\end{array}$ \\
\hline $0-120$ & $\begin{array}{c}9 \cdot 00 \\
0-60\end{array}$ & $\begin{array}{c}8 \cdot 35 \\
2 \cdot 54\end{array}$ & -7 \\
$60-120$ & $4 \cdot 36$ & $5 \cdot 81$ & +45 \\
\hline
\end{tabular}

The synthetic effect can be shown best if slices are shaken with adrenaline for some time before the substrate glucose is added. Again a typical experiment may illustrate this point.
Synthesis of MgM. GLYCogen PER GM. Liver.

Liver slices from rabbit starved 35 hours $(0.55 \mathrm{mgm}$. glycogen $/ \mathrm{gm}$. liver) shaken in Krebs Ringer bicarbonate $(1: 6) 95 \%$ oxygen; $5 \%$ carbon dioxide ; $38^{\circ} \mathrm{C}$.

\begin{tabular}{|l|c|c|c|c|}
\hline & 30 min. $1 \%$ glucose & $\begin{array}{c}30 \text { min. } 1 \% \text { glucose after } \\
60 \text { min. incubation with- } \\
\text { out glucose }\end{array}$ \\
\hline & - & $\begin{array}{c}M \cdot / 100,000 \\
\text { adrenaline }\end{array}$ & - & $\begin{array}{c}M . / 100,000 \\
\text { adrenaline }\end{array}$ \\
\hline Synthesis & $2 \cdot 16$ & $1 \cdot 07$ & $2 \cdot 14$ & $3 \cdot 09$ \\
\hline $\begin{array}{c}\text { Influence of } \\
\text { adrenaline }\end{array}$ & $-50 \%$ & & $+45 \%$ \\
\hline
\end{tabular}

(This work was aided by a grant from the Ella Sachs Plotz Foundation.)

${ }^{1}$ Lehmann, NATURE, 141, 470 (1938).

${ }^{2}$ Gill and Lehmann, Biochem. J., 33, 1151 (1939).

${ }^{3}$ Gill and Lehmann, Chem. Ind., 58, 254 (1939).

- Lehmann, Biochem. J., 33, 1241 (1939).

5 Lee and Richter, Biochem. J., 34, 551 (1940).

${ }^{6}$ Lehmann, NatuRE, 141, 690 (1938).

' Holmes and Lehmann, Brit. J. Exp. Path., 21, 196 (1940).

${ }^{8}$ Fröhlich and Pollak, Arch. exp. Path. u. Pharm., 77, 265 (1914).

- Cross and Holmes, Brit. J. Exp. Path., 18, 370 (1937).

\title{
CONTINUOUS WAVE INTERFERENCE WITH TELEVISION RECEPTION
}

\begin{abstract}
A $\mathrm{N}$ article by C. N. Smyth, of Kolster Brandes, Ltd., Sidcup, on continuous wave interference with television reception, is published in Electrical Communications, 19, No. 4 (1941). Interference with television reception can be very severe due to the large band width employed for this service, and is a much more serious problem than interference with sound broadcasting. Fortunately, however, both have much in common in the methods which can be used to effect suppression.

Interference is divided into two main categories: damped wave or impulsive type interference and continuous wave interference. The former is caused mainly by radiation from the ignition systems of motor vehicles, sparking in electrical machinery and appliances and from harmonics of spark-type transmitters on certain ships. Thermal agitation, noise in eircuits and Schott noise in tubes also produce interference of this type within television receivers. The latter type of interference is caused by radiation from short-wave radio or television receivers, quite apart from any outside sources, due to unwanted couplings between certain circuits causing harmonics of the sound or vision, medical diathermy apparatus used in hospitals, and harmonics from powerful broadcast and amateur transmitters. Continuous wave interference patterns may also be produced within telephone receivers, quite apart from any outward sourees, due to unwanted couplings between certain circuits causing harmonies of the sound or vision intermediate frequencies to react with the incoming signal, or due to hum voltages derived from the power supply frequency and its harmonics, or voltages derived from the harmonics of the scanning frequencies being injected into the receiver picture amplifier.
\end{abstract}

Interference-free reception of sound in television can only be effected if it is possible to locate an aerial where the signal-interference ratio is sufficiently large, and where the signal strength is sufficiently strong, to swamp the effects of losses in the transmission line and interference encountered in the receiver itself; then, providing the receiver is well screened and the power supply adequately filtered, the receiver will reproduce the signal-interference ratio present in the aerial in the frequency pass-band of the receiver. If the signal interference ratio is not sufficiently good, then advantage may be taken of the directional and polarizing properties of aerials, and an aerial employed which receives waves coming only from the effective direction of the transmitter, and with the desired angles of polarization. Beyond this, the signal interference ratio cannot be improved without reduction of picture quality, by reduction of band width or the use of interference suppression circuits which limit the peaks of picture modulation or leave gaps in the picture where interference signals would normally appear. Such interference suppression circuits are only applicable to impulsive type interference.

Further improvement lies in the direction of suppression of the interference at the source, but before this can be undertaken with any certainty of success, it is necessary to have an exact knowledge of the degree of suppression which is desirable.

By continuous wave interference is implied the production of spurious modulation frequencies superimposed on the picture signal in the output of the receiver, and appearing as a steady or slowly changing pattern on the picture screen. This effect is often described as a herring bone or feather pattern superimposed on the picture.

The annoyance value of the interference, that is, its property of destroying the entertainment value of a television programme, depends on the signal to interference ratio on the resultant picture, or what 
is almost the same thing, on the output of the recuiver revision amplifier or on the grid modulating device:

Mr. Smyth has made a series of visual observations and recorded them photographically to study the effects of interference on tesit signals and also on actual programmes. No marked divergence of opinion was expressed by any of the observers as to what did or did not represent interference-free reception. Measurements were also made to determine whether continuous wave interference was more noticeable by reason of its effect on synchronization rather than on modulation of the picture brightness. Several photographs are given which illustrate well the effects of change of frequency on interference.

The main conclusions which have been deduced from Mr. Smyth's observations and tests are as follow. Interference $40 \mathrm{db}$.(decibels) below the level of the picture modulation has no visible effect; at $30 \mathrm{db}$. below a slight effect is produced; while at $20 \mathrm{db}$. or less the entertainment of the picture is seriously reduced. The annoyance value of the interference is not affected by the brightness level at which the picture is reproduced provided the picture is reproduced with reasonable fidelity. A simple picture such as black lettering on a white background without any half-tones can be reproduced without appreciable loss of detail in the presence of considerable interference if the amplifier or light. source is over-modulated in both the black and white directions.

\section{TEAK PLANTATION YIELD TABLES}

$\mathrm{R}$ ECENT research work exemplifies the close col laboration maintained between the Central Research Institute at Dehra Dun, India, and the local research officers maintained in the various provinces of the country. It also furnishes evidence of a wider connexion. The first yield tables for plantation teak were made by Bourne in 1919-21 for the Nilumbur teak plantation situated some fortyfive miles up the Beypur River'from Calicut on the west coast of Madras. This famous plantation was started by the collector of the district, Conolly, in 1844, and was for long regarded as the pioneer in this work. But in Java the Dutch had commenced to plant teak successfully at an earlier date; for in 1932 Dr. Wolff von Wülfing compiled some yield tables for teak plantations in Java which include trees up to one hundred and ten years of age.

Whether teak grown in pure plantations can ever equal in quality of timber the article produced when grown in a mixed forest, which is commonly Nature's own method, is perhaps doubtful. Owing, however, to the much higher price the timber fetches in comparison with that of its associates, it has been planted more extensively than any other single species ; and the cult has spread to Africa where it is an exotic. Existing plantations in India and Burma are now estimated to cover an area of roughly three hundred square miles, and about ten square miles are being added annually.

Until recently Bourne's Nilumbur yield table had been the only standard of reference available for teak grown in even-aged plantations. As it was based on growth measurements obtained from a single plantation it had considerable limitations in its application elsewhere. The Java 1932 yield tables were based on a greater range of quality and age; they were translated by Prof. H. G. Champion into English units ${ }^{1}$. It has been found that the tables recently compiled by the sylviculturist at the Research Institute $^{2}$ compare favourably with those of Dr. Wolff von Wülfing for Java; height-growth trends and the intermediate quality class boundaries for both the Indian and Javan tables almost exactly coincide, thereby rendering it possible to make close comparisons between the data given in the two tables. The authors express their thanks to Dr. Wolff von Wülfing for his permission to reproduce his tables in English units.

1 For. Bulletin No. 87 (1934).

Ind. For. Rec., New Series, Sylviculture. Yield and Stand Tables for Teak Plantations in India and Burma, by V. M. Laurie and Bakehi Sant Ram. (Gov. of India Press, Delhi 1940.)

\section{FORTHCOMING EVENTS}

\section{SATURDAY, NOVEMBER}

SOCIETY OF CHEMTCAL INDUSTRY (Food Group) (Joint meeting with the South Wales Section) (in the Physics Lecture Room, University College, Cardiff), at 3.15 p.m.-Dr. Magnus Pyke : "The Chemical Determination of Vitamins".

\section{MONDAY, NOVEMBER 3}

ROYAL GEOGRAPHICAL SOCIGTY (at Kensington Gore, London, 8.W.7), at 3 p.m.- Sir Jolin Russell, F.R.S.: "Reconstruction and Development in Eastern Poland, 1930-39".

\section{TUESDAY, NOVHMBER}

IN8TTruTroN of CIvIL ENGINEERs (at Great George Street, London, S.W.1), at 2 p.m.-Prof. Charles Edward Inglis, F.R.S.: Presidential Address.

Royar College of Surgeons of Englann (at the Royal Society of Medicine, 1 Wimpole Street, London, W.1), at $2.30 \mathrm{p.m}$.Mr. L. R.
Braithwaite: "The Ileo-Gastric Syndrome" (Moynihan Lecture).

WEDNESDAY, NOVEMBER 5

ROYAL Socrety of ARTs (at John Adam Street, Adelphi, London, W.C.2), at 1.45 p.m.-Sir Edward Crowe: "Co-operation for Production".

THURSDAY, NOVEMBER 6

ROYaL COLLEge of SURGEONS OF ENGLAND (at the Royal Society of Medicine, 1 Wimpole Street, London, W.1), at 3.30 p.m.-Dr. W. E Gye, F.R.S.: "Cancer of the Breast" (Imperial Cancer Research Fund Lecture)

\section{APPOINTMENTS VACANT}

APPLICATIONS are invited for the following appointments on or before the dates mentioned:

acting Headship of The Department of Geography-The Registrar, University College, Hull (November 6).

Lecturer IN Pharmacology-The Secretary and Registrar, University, Bristol (November 8 ).

Gradoate Lecturfr in THE ENGINEering Department-The Gec retary Branch, Cheltenham (November 10).

INFORMATION OFFICER, who should be a graduate in applied science -The Manager, Wrought Light Alloys Development Association, 34, New Street, West Bromwich (November 15).

Organizing Secremary-The Secretary, Association of Assistant Mistresses in Secondary Schools, Stoney Cockbury, Winchcombe, Gloucester (endorsed 'Appointment') (November 25).

RESEaroh Assistant IN Veterinary Sciknor under the Alan, Duke of Northumberland Memorial Fund-The Hon. Secretary, King's College, Newcastle-upon-Tyne (November 29).

Sanion Geography Mistrass-The Headmistress, County School for Girls, Beckenham, Kent (endorsed 'Geography').

Edudation OFHOER-The Wardens, Educational Settlement, Pontypool, Mon.

RESEarch Assistant IN THE EConomics DhParTMENT-The Registrar, University College, Exeter.

Editorial and Publishing Offices
MACMILAN \& CO.. LTD.,
ST. MARTIN'S STREET, LONDON, W.C.2.
Telephone: Whitehall 883! Telegrams : Phusis Lesquare London

